\title{
The Significance of the Earliest Beads
}

\author{
Robert G. Bednarik \\ International Federation of Rock Art Organizations (IFRAO), Melbourne, Australia \\ Email: robertbednarik@hotmail.com
}

Received 12 February 2015; accepted 3 March 2015; published 10 March 2015

Copyright (C) 2015 by author and Scientific Research Publishing Inc.

This work is licensed under the Creative Commons Attribution International License (CC BY).

http://creativecommons.org/licenses/by/4.0/

(c) (i) Open Access

\section{Abstract}

This paper attempts to explore beyond the predictable and banal archaeological explanations relating to early beads and pendants. It recounts replication experiments to establish aspects of technology so as to better understand what can be learnt from the quantifiable properties of these artifacts. The article also scrutinizes the available empirical record in the light of taphonomic logic to translate the known spatial and temporal distributions of such remains into epistemologically meaningful pronouncements about the significance of the primary evidence. It is shown that numerous reasonable deductions become possible by engaging such avenues of inquiry. For instance some beads, in which production has been pushed to the limits allowed by the medium, seem to express a sense of perfection, and it is contended that beads are among the most informative forms of exograms that could possibly have survived from these very early times. A key requisite for the use and appreciation of all beads and pendants is a level of hominin self-awareness that essentially expresses full cognitive modernity.

\section{Keywords}

Bead, Pendant, Replicative Experimentation, Ostrich Eggshell, Taphonomy, Pleistocene, Self-Awareness, Hominin Modernity

\section{Introduction}

In terms of the archaeological information about the way an artifact was produced, how it was used, and what happened to it after it was deposited in what we now consider to be its archaeological context (i.e. its taphonomy), the study of beads and pendants is particularly productive. Beads convey a great deal more information about their makers and users than their history. Technologically alone they illustrate not only the ability to drill through brittle or often very hard materials, but also they imply the use of cordage. The very essence of a bead or pendant is to be threaded onto a string; it would simply be pointless to perforate a small object for another purpose but to pass a string though it. However, the use of cordage also suggests the use of knots, because a string needs to be closed to form a loop to be effective. Although the ends of a string may be joined by means 
other than a knot, e.g. by the use of adhesive or by plaiting, these alternative means are either impracticable or they are technologically even more complex than the use of knotting (Warner \& Bednarik, 1996). It is relevant to note that seafaring, too, is practically impossible without the use of ropes and knotting. The diachronic availability of Pleistocene remains of cordage (Leroi-Gourhan, 1982; Nadel et al., 1994; Pringle, 1997) is of no relevance to the question, because that class of material evidence obviously possesses an exceptionally long "taphonomic lag time” (Bednarik, 1994a). In short, what beads tell us about the technology of the people who used them is well in excess of deductions concerning their manufacture.

Without doubt the technological deductions beads permit us are of great interest, but of perhaps more importance are the cultural and cognitive deductions they make possible. Beads can be used in a number of ways or for several purposes: they may be emblemic, for instance, and provide various forms of information about the wearer and his or her status in society. Availability for marriage, political status, state of mourning might be such possible symbolic meanings. At one level one might believe that beads indicate simply body adornment, but this is almost certainly an oversimplification. Even if vanity were the motivation for wearing such items, stating this explains not why they are perceived as "decorative". The concept itself is anthropocentric; we do not assume that other animals perceive the information imparted by the beads as meaningful. In human culture, however, various forms or levels of meaning may be encoded in such objects, as well as in other kinds of body adornment (tattoos, body painting, cicatrices, infibulation, anklets, armbands, etc.). In ethnography, beads sewn onto apparel or worn on necklaces may signify complex social, economic, ethnic, ideological, religious, or emblemic meanings, all of which are only accessible to a participant of the culture in question. To name just one example: beads or pendants may function as charms; they may be a means of protection against evil spells or spirits. Clearly, no archaeological access exists to such complex meanings and practices. But there is another generic inference to be made from the use of beads: it is impossible to escape the deduction that the people using them must have a clear concept of the self. Without self-awareness, beads are entirely useless pieces of material.

Beads have been the subject of a great deal of anthropological and archaeological attention (e.g. Beck, 1928, 1941; Biggs, 1969; Chen, 1968; Cheng, 1959: 31; Indraningsih, 1985; Karklins, 1987; Nieuwenhuis, 1904). Some of the perhaps most extensive research of pre-Historic beads might be that of Peter Francis and Randolph White. Mistakenly believing that the ivory beads of the French Aurignacian and contemporary Russian traditions are the earliest beads known to us, White (1989, 1992, 1993a, 1993b, 1995) is the principal protagonist of the view that the appearance of beads and pendants coincides with and marks the advent of the Upper Paleolithic. The model of an explosion-like appearance of the Upper Paleolithic derives a great deal of support from this fallacy, which I have tried to correct on various occasions (e.g. Bednarik, 1992a, 1995a, 1995b, 2008). White describes in admirable detail the manufacturing processes of Aurignacian beads of just one material, without having seen or even considered Pleistocene beads outside of France and Russia, or outside the early Upper Paleolithic period (Bednarik, 1995a: 628). Moreover, his understanding of the early Upper Paleolithic is probably severely mistaken: recent evidence from Germany and other parts of Europe render it much more likely that the Aurignacian was a tool tradition of either Neanderthals, or their direct descendants (Bednarik, 2008), and not as White and literally every other Pleistocene archaeologist has believed and claimed until recent years, of fully "modern" humans. His pronouncements concerning the beginnings of bead use, and what it means archaeologically, therefore need to be ignored.

Francis has examined aspects of both archaeological and ethnographic beads in various regions of Asia (1978, 1981, 1982a, 1982b, 1982c, 1985, 1986, 1989a, 1989b, 1989c, 1989d, 1990). In the present context, his experiments with shells (Francis, 1982d) are of particular interest. They are the only replicative work with very early beads that I am aware of, other than my own. Francis considers five techniques of perforating shell beads that he found in the literature: gauging, scratching, sawing, grinding, and hammering. He has applied each of these methods to some shell species, using in all nine species, but he has not applied the most obvious method of perforation, drilling or boring. He does not elaborate on this omission. In beads or pendants other than those made of shell, which are widespread, the perforations are made almost exclusively by rotating action, except for a number of specimens that exhibit some gauging around the perforation (especially teeth). It is to be noted, incidentally, that some pendants lack a perforation altogether, having instead been attached to the supporting string with the help of an incised groove.

Stone implements used for drilling are well known from Lower Paleolithic cultures onwards (Keeley, 1977) and Francis himself reports that in replicating scratching of perforations he found himself "applying rotary motion” (Francis, 1982d: 714). Francis’ five methods of perforation are generally unsuitable for all potential bead 
materials other than shells, including stone, amber, ivory, teeth, and ostrich eggshell, therefore they are of no relevance to the manufacture of most pre-Historic beads and pendants. Shell beads are among the earliest "ornaments” found in many regions, including India (Francis, 1981: 140), China (Cheng, 1959: 31), Australia (Morse, 1993), South Africa (Henshilwood et al., 2004), Morocco (Bouzouggar et al., 2007), and Algeria (McBrearty \& Brooks, 2000); and one of the earliest pendants of Europe, from the Châtelperronian of the Neanderthals, is even made of a fossil cast of a shell (Bednarik, 1995b: Figure 6).

Irrespective of their cultural purpose, beads convey complex information about the wearer, which it would be impossible to create a context for without the use of a communication system such as language. This needs to be emphasized because it leads to the postulate that the use of beads assumes the availability of a complex communication system. We have many other indicators of possible language use during the Lower and Middle Paleolithic (e.g. other forms of "symbolism", or successful ocean navigation), and the very early use of beads and pendants provides similarly crucial evidence that, collectively, renders the hitherto dominant model of cognitive evolution redundant. We can no longer afford to ignore this kind of evidence (Bednarik, 1995a), which I will briefly describe here.

\section{Early Pendants and Beads}

Small, perforated objects of the Pleistocene may have been beads or pendants (Biggs, 1969), or they could have been quangings, pulling handles or buckles as reported ethnographically (e.g. Boas, 1888: Figures 15, 17, 121d; Nelson, 1899: Pl. 17; Kroeber, 1900: Figure 8). However, most of such utilitarian objects are not only of a quite typical shape or design, they exhibit particular wear traces and material properties. To be more specific, small circular or spherical objects with central perforation are considered to be beads, especially where they occur repeatedly. Similarly, objects such as animal teeth, perforated near one end (near the root) are not thought to be pulling handles, nor are objects that are too fragile to function as such utilitarian equipment.

Middle and Lower Paleolithic finds with both artificial and natural perforations are quite common, and have been found since the 19th century. Thousands of such objects are reported in the literature, although there is often no reliable evidence that the perforation is anthropic (cf. Klíma, 1991). Some materials can be perforated by natural processes. For instance, bones can be chewed through by animal canines or partially digested by stomach acids, while mollusk shells are commonly perforated by parasitic organisms. To acquire experience in recognizing such natural perforations I have microscopically examined hundreds of specimens of the latter type. But before hastily omitting objects with natural perforations from all consideration in this context we would do well to remember that the cultural status of such an object is not contingent on whether the hole in it was made by human agency. While it is preferable to rely on specimens bearing clear evidence of human work when dealing with a period from which bead use has not as yet been conclusively demonstrated, it is to be emphasized that the perforation of a bead or pendant certainly does not need to be man-made, as d'Errico and Villa (1997) erroneously assume. On the contrary, naturally perforated objects are commonly used as ethnographic beads (as are perishable materials) and it seems highly likely that such natural objects were also used in the distant past. Indeed, the earliest beads ever used could quite reasonably be expected to have had natural perforations. Thus the determining factor in recognizing pre-Historic beads is not an artificial perforation, but microscopic evidence of wear use. Such evidence consists of two types: the wear occasioned by the string on which the bead is threaded, and the facet-type wear around the hole that results from the rubbing of the adjacent bead on a string, in very prolonged use (Bednarik, 1997a, 2005).

The earliest presumed beads of the Lower Paleolithic were mentioned by Boucher de Perthes (1847-1864) over one and a half centuries ago, occurring together with the first Paleolithic tools ever reported, and from the very type-site of the Acheulian. In the famous paper by Prestwich (1859), in which he recognized the authenticity of the St Acheul stone tools Jacques Boucher de Perthes had been collecting for many years, the occurrence of possible beads is also mentioned. These were reported to be fossilized remains of a sponge, Coscinopora globularis, and Prestwich noted that "some specimens do certainly appear as though the hole had been enlarged and completed" (Prestwich, 1859: 52). Numerous more apparent beads of the same species were found at Acheulian sites, in France and several decades later also in Britain (Smith, 1894: 272-276). Intrigued by these reports, I examined microscopically 325 spherical specimens from Acheulian sites in both countries in 2003, and found that the fossils are not, as assumed until then, of Coscinopora globularis, but that they are of the species Porosphaera globularis Phillips 1829, a Cretaceous sponge (Bednarik, 2005). To my surprise, many of them not only showed considerable human modification of the natural tunnel (the tunnel is partially created by a parasite 
and then modified by humans), but also numerous specimens possessed clear evidence that they were worn on a string (Figure 1). Around both tunnel apertures there were more or less extensive wear facets, in the most pronounced cases amounting to spherical dome-shaped depressions approaching the full size of the bead in question. This, amazingly, had not been noted before, and together with several other forms of evidence it demonstrates beyond reasonable doubts the use of the fossils as beads.

Besides these spherical fossils, circular, disc-like fossil casts have been found at another Acheulian site, the crinoid columnar segments (Millericrinus sp.) from Gesher Benot Ya’aqov, Israel (Goren-Inbar et al., 1991). Here, however, no evidence of wear has been reported, but one specimen has experienced extensive wear from another bead.

Some of the earliest objects with indisputably human-made perforations we know of are the two perforated pendants from the Repolusthöhle in Styria, Austria. If their age estimate is correct, they are in the order of 300,000 years old. One is a wolf incisor, very expertly drilled near its root (Figure 2). The second is a flaked bone point, roughly triangular and perforated near one corner. Both objects were first mentioned by Mottl (1951) but have received little attention since then. They were excavated with a lithic industry variously described as Levalloisian, Tayacian, and Clactonian, which is in fact an undifferentiated Lower Paleolithic assemblage clearly free of Mousterian elements. The occupation deposit was found well below an "Aurignacian" level (more likely Olschewian), separated from it by substantial clastic deposits of stadial periods. There is no reliable dating evidence available, the age estimate is based on the faunal remains, especially the phylogeny of the bear remains. However, it is broadly supported by the typology of the accompanying lithics, which is easiest to reconcile with a late Lower Paleolithic industry.

The more than forty Acheulian ostrich eggshell beads from the Libyan site El Greifa E add an important dimension to the earliest beads we know about. They were recovered with stone tools, such as handaxes, from layers dated by uranium-series analysis to about 200,000 years ago. Initially, only three bead fragments were recovered (Ziegert, 1995; Bednarik, 1997b), but another forty have been found subsequently (Ziegert, 2010). Beads made from ostrich eggshell remain a common feature through the ages, they are found from southern Africa to southern Siberia, und right up to the present time. Because of their importance to appreciating the origins of bead manufacture and use, they are considered separately below.

\section{Middle and Upper Paleolithic Beads}

There are numerous perforated objects also from the (Eurasian) Middle Paleolithic/(African) Middle Stone Age, and many of them may have served as beads or pendants. Forty-one perforated snail shells have been excavated from the Howieson's Poort levels of Blombos Cave, South Africa, and are about 75,000 years old (Henshilwood et al., 2004). The Micoquian has yielded an artificially perforated wolf metapodium as well as a wolf vertebra from the Bocksteinschmiede, Germany (Marshack, 1991). The Micoquian of Prolom 2, Crimea, produced no less than 111 perforated animal phalanges, besides four engraved paleoart objects (Stepanchuk, 1993). Although there is no proof that the phalanges were perforated by human hand, the fact that they are all of one species, Saiga tatarica, and that no perforated bones of other species were found in the cave, suggests that these may also be anthropic perforations. Four deliberately-drilled quartzite flakes from Debenath, Nigeria, and one bone pendant from Grotte Zouhra, Morocco, date from the early Late Pleistocene (McBrearty \& Brooks, 2000).

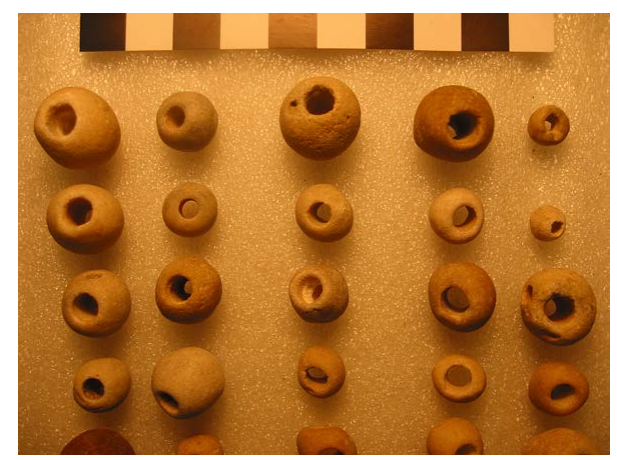

Figure 1. Perforated and worn Porosphaera globularis fossils, used as beads in the Acheulian period. 


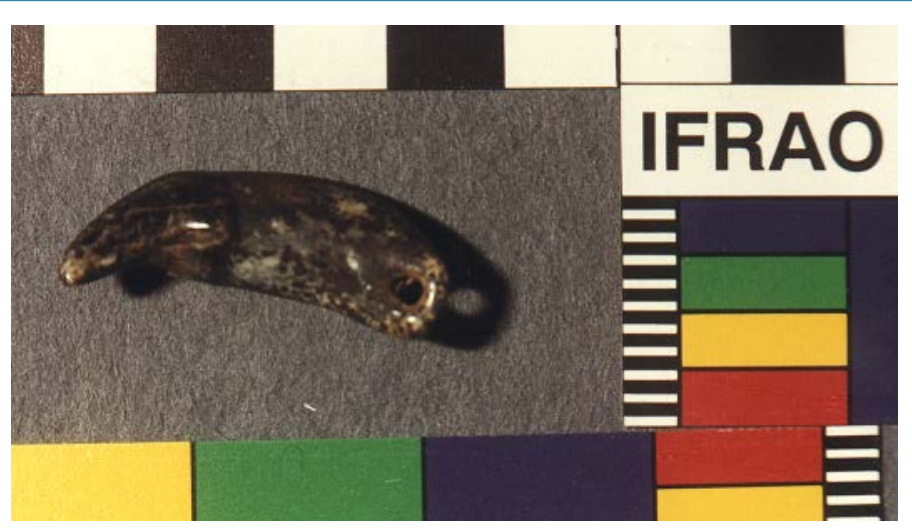

Figure 2. Perforated wolf’s incisor, of a Lower Paleolithic tradition.

The Mousterian of France has yielded a partly-perforated fox canine and a perforated reindeer phalange from La Quina (Martin, 1907-1910), and another perforated bone fragment from Pech de l’Azé (Bordes, 1969). Perforated phalanges and a perforated cranial fragment were recovered from the Mousterian of Lezetxiki, Spain (Baldeon, 1993). The two perforated canines from Bacho Kiro, Bulgaria (Marshack, 1991), too, are of the Middle Paleolithic. As we approach the end of this technological phase, beads and pendants become increasingly common, and materials of stone are now drilled, first appearing in Russia and China. Thirteen such specimens from the lower occupation layer of Kostenki 17, found below a volcanic horizon that is about 40,000 years old, include not only polar fox canines and gastropod shells with perforations, but also stone and fossil cast objects (Bednarik, 1995b: Figure 4). From an intermediate Middle to Upper Paleolithic site in China, wenhua Shiyu, comes a broken stone pendant (Bednarik \& You, 1991), and the oldest presumed beads found in Australia, from Mandu Mandu Creek rockshelter, are about 32,000 years old (Morse, 1993). That country’s earliest known stone pendant is from the final Pleistocene of Devil's Lair, still belonging to a Middle Paleolithic technology (Bednarik, 1997a).

With the advent of the Upper Paleolithic in Eurasia, beads become more numerous and are increasingly manufactured from unwieldy materials, especially ivory. Just three human inhumations at the Russian site Sungir', related to a stone tool technology that is transitional between Middle and Upper Paleolithic implement types, the Streletsian, contained more beads than have been found in the entire Pleistocene sites of the rest of the world. The three graves yielded 13,113 small ivory beads and over 250 perforated canine teeth of the polar fox. By this time, perhaps 28,000 years ago, the art of bead making had reached an extraordinary level, in which the results of thousands of hours of labor were lavished on three burials.

\section{Ostrich Eggshell Beads of Pre-History}

In India we have only a few ostrich eggshell beads from the entire Paleolithic (Bednarik, 1993a, 1993b). Two are from Bhimbetka, south of Bhopal, and three from Patne, Maharashtra. Two of the latter are not perforated, although one is centrally scored. The Bhimbetka specimens were found in the neck region of an Upper Paleolithic human burial (in shelter No. III A-28), so it has been suggested that they formed part of a necklace made up of beads of perishable materials. While the Patne specimens range from $7 \mathrm{~mm}$ to about 10 mm diameter and are rather angular, those from Bhimbetka measure about 6 and $7 \mathrm{~mm}$ respectively and are well rounded. In all, some forty-one Indian sites have yielded fragments of Pleistocene ostrich eggshell (Kumar et al., 1988). Radiocarbon dates ranging from about 39,000 to 25,000 years BP have been cited as relating to these finds. Of the 46 marked fragments I have examined, which are all those that have been found in India so far, 45 bear no anthropic decoration. A natural process I have described in detail, involving mycorrhyzal organisms, marked them and also affects other mineralized calcium carbonate-dominated substances of animal origin (ivory, limestone, bone; Bednarik, 1992b, 1993b).

Other Asian regions producing ostrich eggshell beads are Siberia (KrasnyiYar, Trans-Baykal), Inner Mongolia (Hutouliang) and the Gobi desert in northern China and Mongolia. In particular, an Epipaleolithic or perhaps Mesolithic stone tool industry of the Gobi, usually named after the site of Shabarak-usu, has produced many disc beads, made of freshwater shells as well as ostrich eggshell (Narr, 1966: 366). This tradition, typically of nongeometric microliths, is not dated but seems to precede the local Neolithic (Bednarik \& You, 1991). The ostrich 
(Struthio camelus ssp.), now extinct in Asia (Andrews, 1911), seems to have been widely distributed to the end of the Pleistocene and even well into the Holocene (in Arabia; Bednarik \& Khan, 2005). Depictions of it have been reported from the rock art of Inner Mongolia but their identification has been questioned (Bednarik \& Li, 1991; Tang, 1993).

Both southern and northern Africa have produced finds of worked ostrich eggshell. The southern African sites yielding such finds date from the Middle Stone Age right up to the proto-Historic period. Decorated specimens from the Howieson's Poort phase in Apollo 11 Cave, Namibia (Wendt, 1974), may well be 70,000 - 80,000 years old, even older. This site has also yielded beads made of eggshell from a layer thought to be 22,000 years old. Diepkloof Cave in the south-western Cape, South Africa, contained about a dozen supposedly decorated ostrich eggshell fragments of the Middle Stone Age (Beaumont, 1992). Ostrich eggshell beads from Bushman Shelter near Ohrigstad, Transvaal, have been suggested to date from somewhere between 12,000 and 47,000 years ago (Kumar et al., 1990). Such beads still occur in much more recent periods in southern Africa. For instance they are found in the Smithfield B, a tool complex of the subcontinent's interior regions of the 14th to 17th centuries (Hirschberg, 1966). The use of ostrich eggshell for a variety of purposes, including the production of disc beads and as water vessels, continued to be practiced by the Bushmen of southern Africa until recent times, and has been described ethnographically (e.g. Forde, 1934).

In the far north of Africa, where the ostrich has been extinct for millennia, two pre-Historic periods have provided evidence of the past use of ostrich eggshell: the Capsian and the Acheulian. The Capsian is an Epipaleolithic blade and burin industry in northern Algeria and Tunisia, dating from the first half of the Holocene. It includes not only numerous figurative and non-figurative engravings on ostrich eggshell fragments (Camps-Fabrer, 1966), but also beads of snail shells, teeth and small stones (Camps-Fabrer, 1975: 280-282). Almost any excavation of major Capsian deposits produces ostrich eggshell beads, usually well rounded with central perforation. Containers of wholly preserved ostrich eggshells, too, have been recovered from the Capsian. The decoration they bear suggests that the engraved fragments found in the Capsian deposits may well be from such containers. Saharan rock art depictions convincingly resembling the ostrich are known and may well be of the mid-Holocene. Examples are from Wadi Tilizahren (Jelínek, 1985a: Figures 4, 6, 31, 34, 55, 56; 1985b: Figures 5, 28) and Wadi Mathendous, Fezzan (Striedter, 1984: Figure 7); Tzeretegem, Niger (Striedter, 1984: Figure 187); Iheren, Tassili-n-Ajjer (Striedter, 1984: Figure 125); and North Thyout, Atlas (Muzzolini, 1995: Figure 200).

Of very considerably greater age than the Capsian are the more than forty disc beads from a major Libyan occupation site of the Acheulian (Ziegert, 1995). Also made from ostrich eggshell, they closely resemble those from other regions and later periods (Figure 3). These earliest known ostrich eggshell beads come from the El Greifa site complex (Wadi el Adjal, near Ubari). The site is located on what was a peninsula of the huge Fezzan Lake of the Pleistocene, which then occupied a large part of southwestern Libya, measuring about 200,000 $\mathrm{km}^{2}$. The calcareous sediments have provided excellent preservation conditions for insect remains, seeds, bone, and

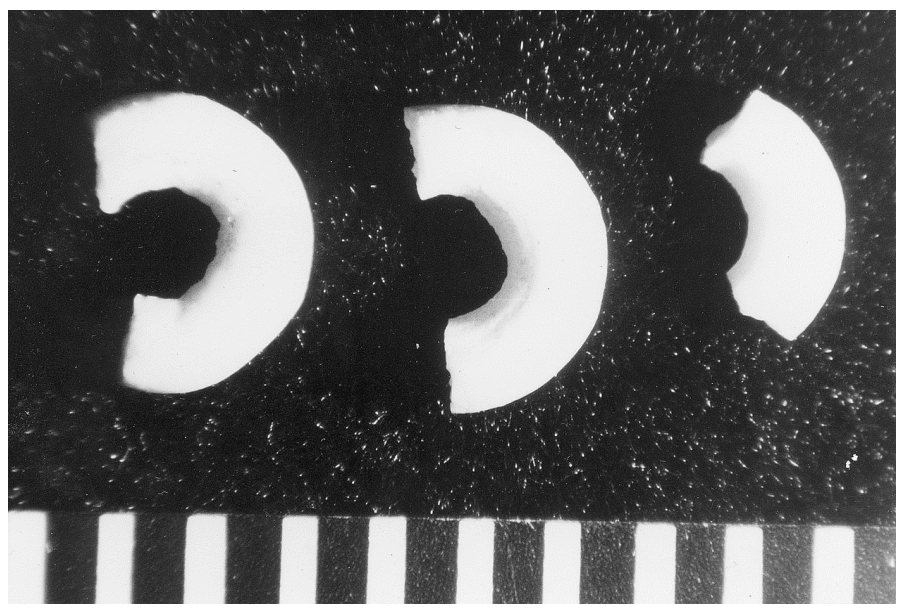

Figure 3. The first three Acheulian ostrich eggshell beads found, c. 200,000 years old, El Greifa, Libya; another forty have since been recovered (scale in $\mathrm{mm}$ ). 
ostrich eggshell fragments. They have also yielded U/Th dating of 200,000 years. At the nearby Budrinna site, the remains of what appears to be a village of round semi-permanent dwelling structures, about 400,000 years old, have been found on the former lakeshore (Ziegert, 2010). There is ample evidence of quarrying of quartzite, and substantial ash beds indicate that the reed belt was annually burnt for a period of many millennia. The sites' lithic inventory includes generally "handaxes", scrapers, borers and burins, but is dominated by large Acheulian types.

\section{The Technology of Ostrich Eggshell Beads}

The near-perfect rounded circumference and perforation of the El Greifa ostrich eggshell beads demonstrate that even hominins of the Late Acheulian possessed a well-developed technology of working this fragile medium with the greatest possible confidence and skill. These perfectly made artifacts also imply the existence of the social structures necessary to provide an ideological context for the production and use of complex body decoration. The first three beads found are preserved as fragments only (c. 58\%, 54\% and 28\% preserved respectively), but they share a similar perforation diameter of about $1.7 \mathrm{~mm}$, and even their external diameter is very consistent (5.8 - $6.2 \mathrm{~mm})$. This consistency in size and the near-perfect rounding of all preserved edges, internal and external, suggests the use of a standardized manufacturing process, a characteristic these beads seem to share with the much later beads of the Upper Paleolithic as well as those of various cultural traditions of the Holocene.

The immediate purpose of my experimental replication work between 1990 and 1996 was to determine the technological processes involved in the production of beads of, and engravings on, ostrich eggshell. The results relating to engravings have been reported (e.g. Bednarik, 1992b); here I will summarize my findings relating to beads, and their implications in terms of the cultural context of their production.

Kumar has conducted experimental replication work with heavily weathered ostrich eggshell fragments collected from Chandresal, which are in the order of 36,000 - 39,000 years old (Kumar et al., 1990: 36). He used Mesolithic stone tools to produce the perforations of two experimental beads, which each took him 10 to 12 minutes to drill through, working from both sides. In my own replication work I have always used fresh ostrich eggshell, because that is what was presumably used in the distant past, and I applied freshly made stone tools of different types and materials to establish relative suitability (Bednarik, 1991, 1992b, 1993b, 1997b). I found it difficult to economically drill through the unweathered shell using thin pointed tools of cryptocrystalline sedimentary silica. The most effective tools for this purpose were found to be rather coarse-grained quartzites and quartz. With them I initially reported drilling through the shell of a complete ostrich egg in times ranging from 70 to 90 seconds, i.e. working from just one side (Bednarik, 1991).

I have subsequently found it easy to reconstruct the production processes for these beads. The raw material is of unusually consistent properties: the shell thickness is uniform, as is the three-layered morphology of the shell (described in admirable detail by Sahni et al., 1990). The only significant material variable is attributable to the shell's curvature, which is of a smaller radius at the ends of the egg than it is along the sides. My replication work soon established that the manufacture procedure used followed a specific pattern, as demanded by the morphology and dimensions of the end product, work traces and the nature of the available stone implements. For instance I found that it was difficult and uneconomical to first shape the bead and then drill it, and that it was marginally easier to drill from the concave side than from the convex. Thus experimentation succeeded in reconstructing the work process quite convincingly, which it seems was as follows.

Once drained of its contents, an ostrich egg was dried and broken into fragments. These were then reduced further, into polygonal pieces of about $1-2 \mathrm{~cm}^{2}$ area. This was done by carefully breaking the shell between fingers, probing for already existing fracture lines. The small fragments were then drilled individually, which is a little more difficult than drilling into the complete egg (Figure 4). An experienced operator takes between 70 and 145 seconds (average 121 secs, $n=11$ ) to perforate the dry shell from one side. (I consider that I became an "experienced operator" after attempting to produce 25 or 30 beads, and quantitative production details reported here refer only to subsequent work.) No significant differences in drilling time were noted according to direction (from outside or inside), but the outer veneer $(<0.1 \mathrm{~mm}$; Sahni et al., 1990) is somewhat harder to start from, and is of course of convex surface, so I came to prefer the concave mammilary innermost layer (Sahni et al., 1990: Figure 2) to start drilling from. Contrary to various opinions stated, I do not believe that ostrich eggshell beads were usually drilled from both directions, as it is very difficult to meet up with the center of the first opposite indentation. It is much easier to ream out the opening once the boring tool breaks through, using the point of a thin prismatic sliver of chert. I propose that this is the way ostrich eggshell beads were customarily perforated. 


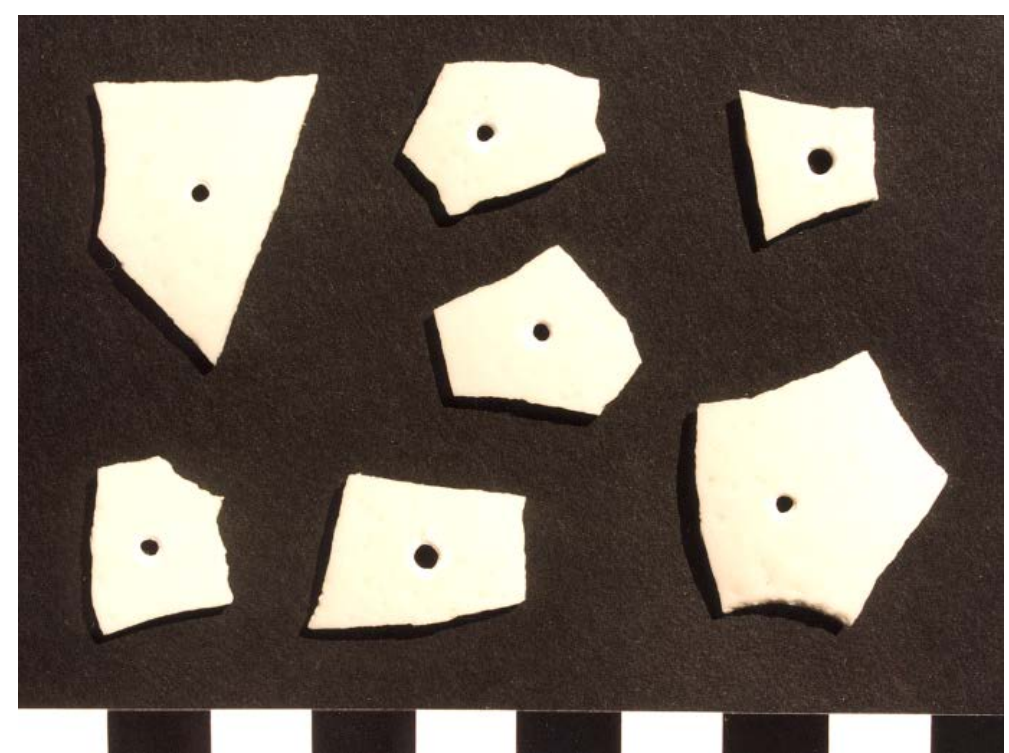

Figure 4. Some of the bead blanks in replication experiments after creating polygonal fragments of the ostrich eggshell and drilling them with stone tools (scale in $\mathrm{cm}$ ).

I also drilled shell fragments soaked in water for 24 hours, taking from 80 to 140 seconds (average 118 secs, $\mathrm{n}$ $=11$ ), which suggests that this does not affect workability of the shell. The principal variable in drilling time is clearly the quality of the stone tool point, and this can vary considerably. In my replicative work I used a variety of stone tool materials, including cryptocrystalline flint, microcrystalline cherts of various types, chalcedony, coarse and fine quartzites, and quartz crystal. I also tried out a variety of tool morphologies, finding that thin points became blunt very quickly, as did finely-grained materials. Nevertheless, all materials I used necessitated the application of two or more points to produce a single perforation economically, so the time of making or resharpening borers has to be added to production time. Stout angular points on flakes or blades of $1-2 \mathrm{~mm}$ thickness at their end were found to be the most effective, and excessive pressure is counterproductive as it accelerates the wear of the tool point exponentially.

Once the perforation is complete it is reamed out from the other (convex or outer) side, using slender bladelets or prismatic points, which may be more fragile. The duration of this process depends on the desired hole diameter, but in about one minute an even diameter of around $2 \mathrm{~mm}$, eliminating much of the drilling cone, can be attained. It is clear from my work that the three perforated beads of the Indian Upper Paleolithic were reamed out by alternating rotation of the borer: this usually results in a slightly oblong perforation, as already noted by Semenov (1964: 78) in drilling through other materials with stone tools.

Before commencing the abrading of the still angular fragment, the excess area is trimmed off by gripping the piece firmly between two fingers in the area that is to form the final bead, and pressing its convex side against a stone surface (Figure 5). This process of snapping off small angular fragments until the actual bead blank is obtained requires skill and judgment: if the bead is incorrectly held or handled, it can easily crack through the perforation. The average time of the trimming process is 34 seconds.

Grinding the excess material from the fragment's edge is easy, although very demanding on the operator's fingertips. I found it convenient to divide this process into two steps, first grinding the bead blank into a roughly circular shape of under $10 \mathrm{~mm}$, resembling the Patne specimen from India. This requires between 65 and 270 seconds (mean 217 secs, $n=12$ ), the duration being related directly to the amount of excess material to be removed. Siliceous sandstone, silcrete, or quartzite provide excellent grinding surfaces, and an experienced craftsman should not break any pieces in this process (Figure 6).

Ethnographic specimens of disc beads are sometimes manufactured by a method called the heishi technique, named after the Santo Domingo Pueblo Indian word for "shell bead" (New Mexico, USA). The heishi technique was a widespread method of mass-producing beads from ostrich eggshell and other thin materials, in which the perforated blanks are threaded onto a rod or stiff fiber, the entire set is ground together, resulting in 


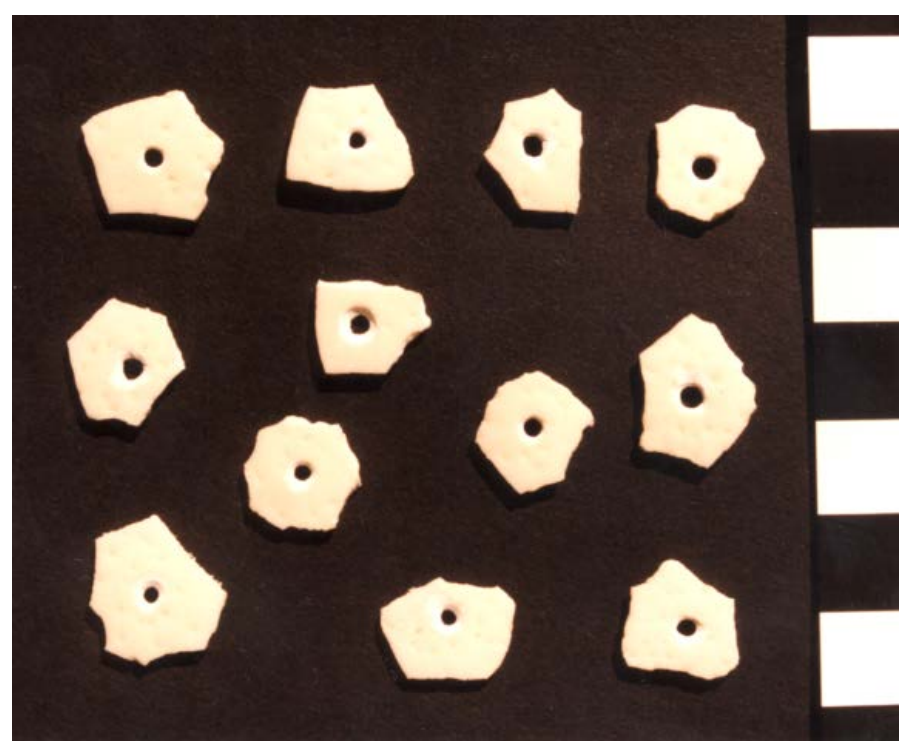

Figure 5. Bead blanks after excess material is trimmed off by pressure (scale in $\mathrm{cm}$ ).

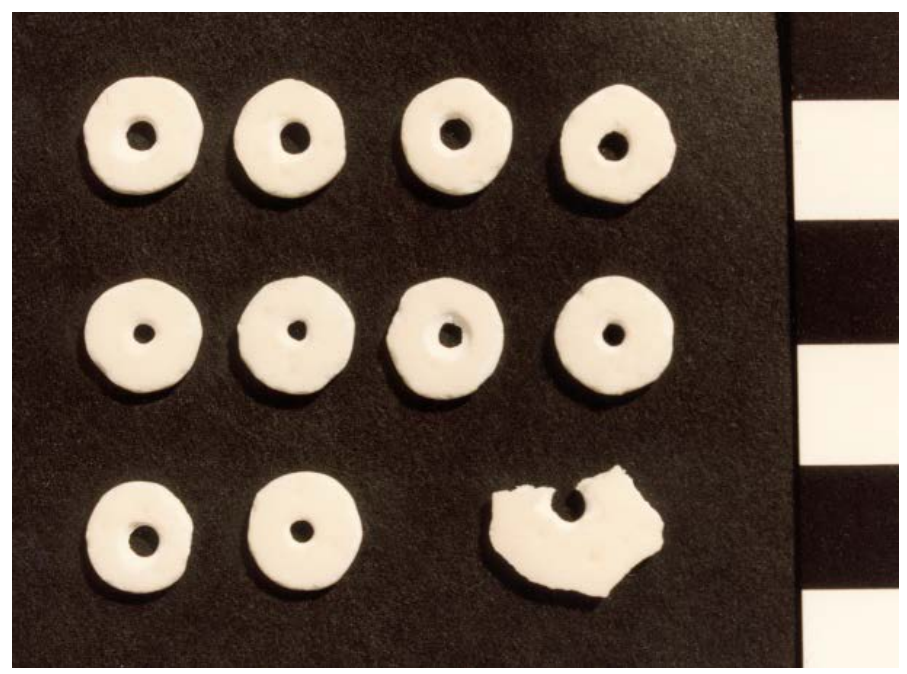

Figure 6. Some of the 65 ostrich eggshell beads I made with stone tools, at the stage of reaching a diameter of about $10 \mathrm{~mm}$. Note that one specimen broke in the edge-grinding process.

very consistent sizes and shapes (Francis, 1990: 47). I emphasize, however, that I have observed no evidence that this method was used in the Paleolithic period, anywhere in the world. Most particularly, the few Indian specimens we have were made singly (contra Francis, 1982, 1990).

In attempting to replicate the Acheulian specimens from El Greifa, I found that I had to further refine the product of the last step. It takes between 580 and 645 seconds to reduce the $<10 \mathrm{~mm}$ beads to almost perfectly round specimens of about $6 \mathrm{~mm}$ diameter (mean 618 secs, $n=12$ ). On this basis we can estimate that the time it took to produce one of the El Greifa ostrich eggshell beads, assuming that the maker was a skilled craftsman, was in the order of 17 minutes, or about 25 minutes if we include the time of preparing and resharpening stone points (Figure 7).

Both the beads and the stone tools used in their manufacture were examined under a stereoscopic optical microscope at low to medium magnifications. The information so gained is not only useful in the microscopic study of pre-Historic bead specimens and stone borers, it also explained the surprisingly rapid blunting I experienced with the stone tools. Expecting to find significant microscopic spalling on working edges, I was sur- 


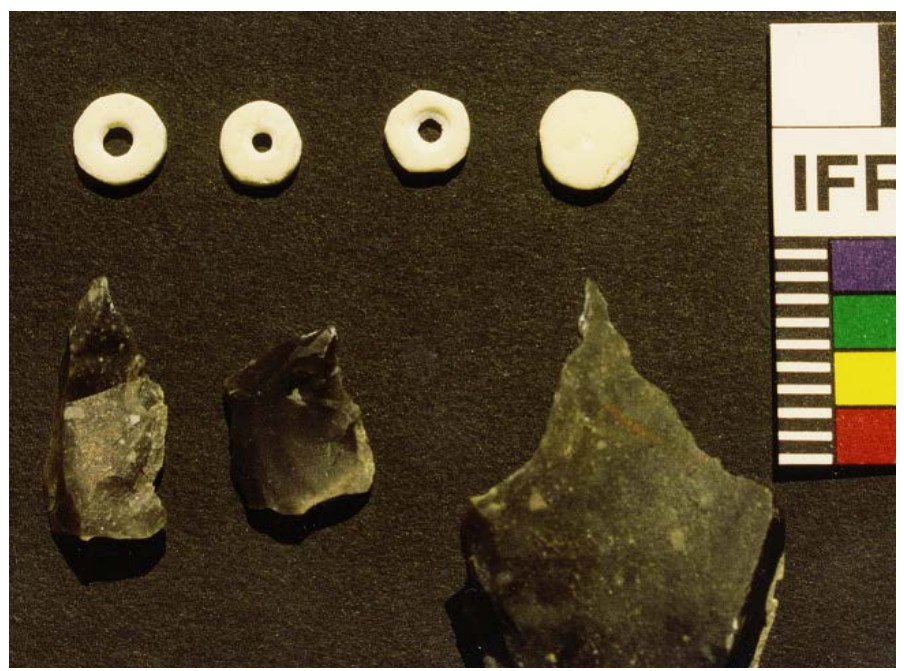

Figure 7. Experimental ostrich eggshell beads ground to about $6 \mathrm{~mm}$ diameter, with some of the chert borers or reamers used in drilling them.

prised to see that the "blunting" of borers was not so much due to wear, but due to clogging up of recesses with compacted calcium carbonate. Nevertheless, a characteristic type of wear sheen was also noted on the edges at the point of many tools.

The ground and powdered eggshell material was also examined carefully, and was found to contain surprisingly large chips of eggshell layer, commonly measuring $0.1-0.5 \mathrm{~mm}$, but in rare cases of up to $1.8 \mathrm{~mm}$ length. However, over half the volume of the white powder is of much smaller grain-size, most of it 2 - $20 \mu \mathrm{m}$. Differences in its composition were noted according to the rock type used: a gritty siliceous sandstone and a silcrete produced slightly different cumulative grain size distribution curves than a dense central Indian quartzite.

\section{Discussion}

To appreciate the significance of flat disc beads manufactured from ostrich eggshell, and their role in interpreting the cognitive evolution of humans, two factors need to be considered first: the distributions, in both time and space, of such finds, and then the taphonomic explanation of both these distributions. Disc beads such as those made from ostrich eggshell are a form of artifact that is not likely to have been made singly or in very small numbers. To provide such symbolic objects with a social meaning it would have been essential that they were made in quite large numbers, because it is repeated and "structured" use which confers meaning on "symbolic" artifacts. The role of beads, as well as pendants, would have always been non-utilitarian, ideological, emblemic, or "symbolic". Moreover, very small beads such as those made from ivory or ostrich eggshell were probably not worn singly, because to achieve a decorative effect they are generally worn as sets in ethnographic specimens.

This renders it necessary to explain why-wherever ostrich eggshell beads have been found in Pleistocene contexts-only extremely small numbers were recovered. Moreover, why are the few known occurrences so extremely isolated in both time and space? Major intervening time spans have yielded no such artifacts, nor have vast geographic regions in which the ostrich is known to, or can be assumed to, have occurred. Taphonomic logic offers the most realistic explanation for this pattern of distribution (Bednarik, 1986, 1992c, 1994a). Accordingly we are almost certainly dealing with a phenomenon of a very long taphonomic lag time. The extreme paucity of Pleistocene finds can readily be explained by postulating that they survived only in minute numbers from beyond the taphonomic threshold of the phenomenon category in question (Bednarik, 1994a: Figure 2).

The present synopsis of Pleistocene bead remains might convey the impression that beads were produced infrequently for more than 200,000 years, and then became much more numerous with the advent of the Upper Paleolithic. While this is remotely possible it must be cautioned that this pattern of distribution in time provides a typical parabolic curve as demanded by taphonomic logic. Accordingly the advent of the Upper Paleolithic should NOT indicate the advent of frequent bead manufacture, but merely the taphonomic threshold of this phenomenon category. The taphonomic threshold of ostrich eggshell is presumably somewhat later than that of 
ivory. This is almost certainly the correct explanation of the evidence available to us, in which case that record must be tempered by taphonomic logic before it can be interpreted.

The strong hypothesis that humans of the Late Acheulian period, by 200,000 years ago at the very latest but probably considerably earlier, possessed cultural systems involving bead production and use is at considerable odds with the currently dominant paradigm. Not only does it postulate a value system concerning purely abstract criteria, there must have been a socially shared and communicated meaning regarding the significance of the characteristics of these symbolic products. There can be no purpose in producing technological perfection if there is no comprehension and appreciation of its ideals, be it by the maker, the wearer or the beholder.

A related insight provided by the Lower Paleolithic beads concerns their technological perfection. It suggests that their makers drew from the experience of a long tradition of manufacturing such products. Perforation of hard objects (e.g. teeth) was probably already practiced early, and very competently. Bearing in mind that most ethnographically known beads are of perishable materials, we may reasonably assume that this also applied in the distant past. Naturally perforated small objects may have been used as beads, such as crinoid columnar segments (Goren-Inbar et al., 1991) or the ear-bone of the cave bear (Marshack, 1991: Figure 6), and were certainly used in the form of Porosphaera globularis fossils. Finally, but perhaps most importantly, taphonomic logic simply demands a much earlier commencement of the use of beads than can be detected on the fossil record (Bednarik, 1994a).

The excellent rounding of the circumferential edge of the Acheulian eggshell beads and the even width of the ring indicate a conscious appreciation of an essentially abstract, geometric form by 200,000 BP at the latest, an appreciation which is amply evident from the later Middle Paleolithic technological traditions. The latter period has provided such evidence from Hungary (the Tata nummulite; Bednarik, 1992a: Figure 4) to Australia (the extensive geometric rock art of that country's Pleistocene tradition, which is the world's most recent Middle Paleolithic; Bednarik, 2010).

Mainstream archaeologists may find such evidence of early sophistication extraordinary, but seen in the wider context of other finds of the general period in question it should be neither unexpected nor controversial (Bednarik, 1995a, 1997c). Even Homo erectus must have had language to navigate the sea and colonize new islands (Maringer \& Verhoeven, 1970, 1977; Bednarik, 1997c, 2003, 2014a). Petroglyphs, too, were produced in the Lower Paleolithic, and hematite or other iron compounds were used as pigment up to a million years ago (Bednarik, 1994b, 2013), while hafted tools with wooden handles, stone-walled dwellings and portable engravings all date from the Lower Paleolithic (Bednarik, 1992a, 1995a, 1996). It is unfortunate that the dominant models in archaeology, since the time of the rejection of the Altamira art over a century ago, remain largely determined by faddish and false notions about the capabilities of the ancients.

The principal reason for the importance of the subject of this paper has not yet been considered. Beads and pendants, like other forms of body adornment, provide not only a great deal of exogrammatic information (Bednarik, 2014b) about their wearer (cultural, social, economic, ethnic, ideological, religious, or emblemic) and maker (sense of perfection). More importantly, they witness the existence in their users of advanced selfawareness: without self-awareness there can be no conscious body adornment. The sentience of one's own knowledge, attitudes, opinions, and existence exists at various levels in different species. Some of the great apes, the elephants, and bottlenose dolphins are among the species that have passed the mirror test (De Veer \& Van Den Bos, 1999; Gallup, 1970; Gallup et al., 2002; Heyes, 1998; Keenan et al., 2003; Mitchell, 1993, 1997, 2002; but see Swartz, 1997; Morin, 2003 for critical reviews), and interestingly they are much the same species shown to possess von Economo neurons (Seeley et al., 2006; Butti et al., 2009; Hakeem et al., 2009; Helvenston \& Bednarik, 2011). But the ability of involving exograms in constructing concepts of the self appears to be limited to humans (Bednarik, 2012a), and since the use of exograms is the only characteristic that differentiates humans fundamentally from other animals, it is reasonably to say that the significance of beads is vastly greater than simplistic archaeology could possibly appreciate.

\section{Conclusion}

The replication of archaeological specimens is part of experimental archaeology, without which interpretation in this discipline is of very limited use. It is through the experimentation with technologies that we gain credible insights into how materials must have been utilized to produce the kind of record the archaeologist encounters. In this sense experimental archaeology is related to the study of the taphonomy of archaeological remains, and 
together these two areas of research can bring archaeological interpretation to life, as hopefully demonstrated in this paper.

The most consequential deductions we can draw from the present study concern the Acheulian beads from Libya, and what we can learn about the circumstances of their manufacture, in terms of illuminating the cognitive world of their makers. The first observation we can make concerns the considerably finer workmanship of these Acheulian specimens in comparison to those we have of the Upper Paleolithic. This may be unexpected, but it mirrors an experience we had recently with European rock art: the most sophisticated we have found so far, that of Chauvet Cave in France, turned out to be also some of the earliest we know of in the Upper Paleolithic (Clottes et al., 1995) and is attributable not to "anatomically modern humans", but to Neanderthaloids (Bednarik, 2007). Hence the idea of evolution toward increased sophistication is a Eurocentric myth in rock art development, and may well be so in other areas of archaeology.

The near-perfect roundness of the Acheulian beads can be obtained only by constant checking of the shape during the final abrading process, using not just a developed sense of symmetry, but possessing a very clear concept of a perfect geometric form. This roundness cannot be the result of chance or some "instinct" driven by a mere desire to reduce the size of the beads. It is the outcome of a very clear abstract construct of form-a concept-mediated, geometrically perfect form. Moreover, it is the result of a determined effort to produce highquality work. To extract the full potential information offered by these early beads, I find the following point particularly relevant, and it also demonstrates vividly the great benefits of replication studies.

During my experiments I found that as the beads are ground to a diameter of 8 or $7 \mathrm{~mm}$ it becomes increasingly difficult to hold them while grinding them, and after a time it becomes a rather painful task. The fingertips not only have to maintain a tight grip, they are also subjected to abrasion from the coarse siliceous stone. About $6 \mathrm{~mm}$ is the diameter at which it becomes uneconomical to continue reduction further, and this is precisely the size of the Acheulian bead fragments. This, too, is not a coincidence, but the result of a deliberate decision to reduce the beads to the smallest realistically possible size. At sizes of under $6 \mathrm{~mm}$, the beads become increasingly fragile: with a perforation of almost $2 \mathrm{~mm}$, their rim width falls to under $2 \mathrm{~mm}$. Moreover, because of what remains of the bi-conical perforation profile, the innermost part of the rim is never of full eggshell thickness. I found that if the beads were ground to a smaller size, they would become susceptible to fracture, either during manufacture or subsequent use.

So we have two limits on minimum size imposed by practical considerations, and we need to ask: why did the makers of these beads push their technology to its practical limits? After all, a larger bead is much easier to see, yet a smaller bead represents a significantly greater work effort. This observation coincides with the already mentioned geometric perfection of the form, which is most certainly deliberate. The most parsimonious explanation for both the size and the form of these objects is that these characteristics reflect a highly developed abstract value system and a considerable social complexity in the society that made and used these beads 200,000 years ago. Without a cultural impetus placing value and meaning on such perfect forms, and on a standard of craftsmanship that pushes the available technology to the utmost limit, there is certainly no practical explanation to account for them. So the motivation of these artisans is to be found in an emerging sense of perfection hundreds of thousands of years ago, in the service of an advanced self-awareness well beyond that determined by the mirror test. This evidence therefore implies that cognitive modernity was well established by the time of the Acheulian (Bednarik, 2012b).

\section{References}

Andrews, C. W. (1911). Notes on Some Fragments of Fossil Egg Shell of a Large Struthious Bird from Southern Algeria, with Some Remarks on Some Pieces of Egg Shell of an Ostrich from Northern India. In H. Schalow (Ed.), Verhandlungen des 5. Internationalen Ornithologen-Kongresses, Berlin 1910 (p. 173). Berlin: Deutsche Ornithologische Gesellschaft.

Baldeon, A. (1993). El yacimiento de Lezetxiki (Gipuzkoa, País Vasco). Los niveles musterienses. Munibe, 45, 3-97.

Beaumont, P. (1992). The Time Depth of Aesthetic and Symbolic Behaviour in Southern Africa. Paper Presented to the Biennial Conference of the Southern African Association of Archaeologists, 1992, Johannesburg.

Beck, H. C. (1928). Classification and Nomenclature of Beads and Pendants. Archaeologia, 77, 1-76. http://dx.doi.org/10.1017/S0261340900013345

Beck, H. C. (1941). The Beads from Taxila. Memoirs of the Archaeological Survey of India 65, Delhi. 
Bedanrik, R. G. (2007). Antiquity and Authorship of the Chauvet Rock Art. Rock Art Research, 24, 21-34.

Bednarik, R. G. (1986). Parietal Finger Markings in Europe and Australia. Rock Art Research, 3, 30-61.

Bednarik, R. G. (1991). Comment on F. d'Errico, "Microscopic and statistical criteria for the identification of prehistoric systems of notation”. Rock Art Research, 8, 89-91.

Bednarik, R. G. (1992a). Palaeoart and Archaeological Myths. Cambridge Archaeological Journal, 2, 27-43. http://dx.doi.org/10.1017/S0959774300000457

Bednarik, R. G. (1992b). Natural Line Markings on Palaeolithic Objects. Anthropologie, 30, 233-240.

Bednarik, R. G. (1992c). The Stuff Legends in Archaeology Are Made of: A Reply to Critics. Cambridge Archaeological Journal, 2, 262-265. http://dx.doi.org/10.1017/S0959774300000640

Bednarik, R. G. (1993a). Palaeolithic Art in India. Man and Environment, 18, 33-40.

Bednarik, R. G. (1993b). About Palaeolithic Ostrich Eggshell in India. Indo-Pacific Prehistory Association Bulletin, 13, 3443. http://dx.doi.org/10.7152/bippa.v13i0.12036

Bednarik, R. G. (1994a). A Taphonomy of Palaeoart. Antiquity, 68, 68-74.

Bednarik, R. G. (1994b). Art Origins. Anthropos, 89, 169-180.

Bednarik, R. G. (1995a). Concept-Mediated Marking in the Lower Palaeolithic. Current Anthropology, 36, 605-634. http://dx.doi.org/10.1086/204406

Bednarik, R. G. (1995b). Towards a Better Understanding of the Origins of Body Decoration. Anthropologie, 33, $201-211$.

Bednarik, R. G. (1996). Lower Palaeolithic Hafting Evidence. The Artefact, 19, 99.

Bednarik, R. G. (1997a). Pleistocene Stone Pendant from Western Australia. Australian Archaeology, 45, 32-34.

Bednarik, R. G. (1997b). The Role of Pleistocene Beads in Documenting Hominid Cognition. Rock Art Research, $14,27-41$.

Bednarik, R. G. (1997c). The Initial Peopling of Wallacea and Sahul. Anthropos, 92, 355-367.

Bednarik, R. G. (2005). Middle Pleistocene Beads and Symbolism. Anthropos, 100, 537-552.

Bednarik, R. G. (2008). The Mythical Moderns. Journal of World Prehistory, 21, 85-102. http://dx.doi.org/10.1007/s10963-008-9009-8

Bednarik, R. G. (2010). Australian Rock Art of the Pleistocene. Rock Art Research, 27, 95-120.

Bednarik, R. G. (2012a). An Aetiology of Hominin Behaviour. HOMO_Journal of Comparative Human Biology, 63, 319335.

Bednarik, R. G. (2012b). The Origins of Human Modernity. Humanities, 1, 1-53.

Bednarik, R. G. (2013). Pleistocene Palaeoart of Africa. Arts, 2, 6-34. http://www.mdpi.com/2076-0752/2/1/6

Bednarik, R. G. (2014a). The First Mariners (2nd ed.). Saarbrücken: Lambert Academic Publishing.

Bednarik, R. G. (2014b). Exograms. Rock Art Research, 31, 47-62.

http://www.ifrao.com/wp-content/uploads/2014/06/31-1-Exograms.pdf

Bednarik, R. G., \& Khan, M. (2005). Scientific Studies of Saudi Arabian Rock Art. Rock Art Research, 22, 49-81.

Bednarik, R. G., \& Li, F. S. (1991). Rock Art Dating in China: Past and Future. The Artefact, 14, 25-33.

Bednarik, R. G., \& You, Y. Z. (1991). Palaeolithic Art from China. Rock Art Research, 8, 119-123.

Biggs, H. E. J. (1969). Mollusca from Human Habitation Sites and the Problem of Ethnological Interpretation. In D. Brothwell, \& E. Higgs (Eds.), Science in Archaeology. London: Thames and Hudson.

Boas, F. (1888). The Central Eskimo. Lincoln: University of Nebraska Press.

Boucher de Perthes, J. (1847-1864). Antiquités Celtiques et Antédiluviennes. Paris: Treuttel et Wurtz.

Bouzouggar, A., Barton, N., Vanhaeren, M. et al. (2007). 82,000-Year-Old Shell Beads from North Africa and Implications for the Origins of Modern Human Behavior. Proceedings of the National Academy of Sciences of the United States of America, 104, 9964-9969. http://dx.doi.org/10.1073/pnas.0703877104

Butti, C., Sherwood, C. C., Hakeem, A. Y., \& Allman, J. M. (2009). Total Number and Volume of Von Economo Neurons in the Cerebral Cortex of Cetaceans. Journal of Comparative Neurology, 515, 243-259. http://dx.doi.org/10.1002/cne.22055

Camps-Fabrer, H. (1966). Matière et art mobilier dans la préhistoire nord-Africaine et Saharienne. Mémoires du CRAPE, Paris.

Camps-Fabrer, H. (1975). Un gisement Capsien de faciès Sétifien, Mendjez II, El-Eulma (Algérie). Paris: Éditions du Centre National de la Recherche Scientifique.

Chen, C. L. (1968). Material Culture of the Formosan Aborigines. Taipei: Taiwan Museum.

Cheng, T. K. (1959). Archaeology in China, Volume 1, Prehistory China. Cambridge: Heffer. 
Clottes, J., Chauvet, J. M., Brunel-Deschamps, E., Hillaire, C., Daugas, J. P., Arnold, M., Cachier, H., Evin, J., Fortin, P., Oberlin, C., Tisnerat, N., \& Valladas, H. (1995). Les peintures paléolithiques de la Grotte Chauvet-Pont d'Arc, à Vallon-Pont-d’Arc (Ardèche, France): Datations directes et indirectes par la méthode du radiocarbone. Comptes Rendus de l'Académie des Sciences de Paris, 50, 1133-1140.

d'Errico, F., \& Villa, P. (1997). Holes and Grooves: The Contribution of Microscopy and Taphonomy to the Problem of Art Origins. Journal of Human Evolution, 33, 1-31. http://dx.doi.org/10.1006/jhev.1997.0141

De Veer, M. W., \& Van Den Bos, R. (1999). A Critical Review of Methodology and Interpretation of Mirror Self-Recognition Research in Nonhuman Primates. Animal Behavior, 58, 459-468.

http://dx.doi.org/10.1006/anbe.1999.1166

Forde, C. D. (1934). Habitat, Economy and Society. London: Methuen.

Francis, P. (1978). The Historical Import of Beads. Bead Journal, 3, 28-29.

Francis, P. (1981). Early Human Adornment in India, Part 1. The Upper Palaeolithic. Bulletin of the Deccan College Postgraduate and Research Institute, 40, 137-144.

Francis, P. (1982a). The Ostrich, Ostrich Eggshells, and Ostrich Eggshell Beads. Man and Environment, 7, 142-146.

Francis, P. (1982b). Indian Agate Beads. World of Beads Monograph Series 6, Lake Placid, NY: Lapis Route Books.

Francis, P. (1982c). The Glass Beads of India. World of Beads Monograph Series 7, Lake Placid, NY: Lapis Route Books.

Francis, P. (1982d). Experiments with Early Techniques for Making Whole Shells into Beads. Current Anthropology, 23, 713-714. http://dx.doi.org/10.1086/202925

Francis, P. (1985). A Survey of Beads in Korea. Occasional Papers of the Center for Bead Research 1, Lake Placid, NY.

Francis, P. (1986). Bead Report XVII: The Asian Bead Study Tour, Part III: A Tale of Two Bead Making Cities. Ornament, 9, 53-58.

Francis, P. (1989a). Beads and Bead Trade in Southeast Asia. Contributions of the Center for Bead Research 4, Lake Placid, NY.

Francis, P. (1989b). The Type Collection of Beads in the Phillipine National Museum. Contributions of the Center for Bead Research 5, Lake Placid, NY.

Francis, P. (1989c). Heirloom and Ethnographically Collected Beads in Southeast Asia. Contributions of the Center for Bead Research 6, Lake Placid, NY.

Francis, P. (1989d). The Manufacture of Beads from Shell. In C. F. Hayes III (Ed.), Proceedings of the 1986 Shell Bead Conference: Selected Papers (pp. 25-36). Research Records 20, Rochester, NY: Rochester Museum and Science Center.

Francis, P. (1990). Two Bead Strands from Andhra Pradesh, India. Asian Perspectives, 29, 45-50.

Gallup Jr., G. G. (1970). Chimpanzees: Self Recognition. Science, 167, 86-87. http://dx.doi.org/10.1126/science.167.3914.86

Gallup Jr., G. G., Anderson, J. L., \& Shillito, D. P. (2002). The Mirror Test. In M. Bekoff, C. Allen, \& G. M. Burghardt (Eds.), The Cognitive Animal: Empirical and Theoretical Perspectives on Animal Cognition (pp. 325-333). Chicago, IL: University of Chicago Press.

Goren-Inbar, N., Lewy, Z., \& Kislev, M. E. (1991). Bead-Like Fossils from an Acheulian Occupation Site, Israel. Rock Art Research, 8, 133-136.

Hakeem, A. Y., Sherwood, C. C., Bonar, C. J., Butti, C., Hof, P. R., \& Allman, J. M. (2009). Von Economo Neurons in the Elephant Brain. Anatomical Records, 292, 242-248. http://dx.doi.org/10.1002/ar.20829

Helvenston, P. A., \& Bednarik, R. G. (2011). Evolutionary Origins of Brain Disorders in Homo sapiens sapiens. Brain Research Journal, 3, 113-139. http://www.ifrao.com/wp-content/uploads/2015/01/HelvenstonBednarik2011.pdf

Henshilwood, C., d’Errico, F., Vanhaeren, M., van Niekerk, K., \& Jacobs, Z. (2004). Middle Stone Age Shell Beads from South Africa. Science, 304, 404. http://dx.doi.org/10.1126/science.1095905

Heyes, C. M. (1998). Theory of Mind in Nonhuman Primates. Behavioural and Brain Sciences, 21, 101-134. http://dx.doi.org/10.1017/S0140525X98000703

Hirschberg, W. (1966). Späte Jäger- und Sammlerkulturen Süd- und Ostafrikas. In K. J. Narr (Ed.), Handbuch der Urgeschichte, Band 1: Ältere und Mittlere Steinzeit. Jäger- und Sammlerkulturen (pp. 368-381). Bern and München: Francke Verlag.

Indraningsih, J. R. (1985). Research on Prehistoric Beads in Indonesia. Bulletin of the Indo-Pacific Prehistory Association, 6. http://dx.doi.org/10.7152/bippa.v6i0.11245

Jelínek, J. (1985a). Tilizahren, the Key Site of the Fezzanese Rock Art, Part I. Anthropologie, 23, 125-165.

Jelínek, J. (1985b). Tilizahren, the Key Site of the Fezzanese Rock Art, Part II. Anthropologie, 23, 223-275.

Karklins, K. (1987). Some Comments on Mulberry and Twisted Square Beads. Bead Forum, 11, 12-14. 
Keeley, L. H. (1977). The Function of Paleolithic Flint Tools. Scientific American, 237, 108-126. http://dx.doi.org/10.1038/scientificamerican1177-108

Keenan, J. P., Falk, D., \& Gallup, G. C. (2003). The Face in the Mirror: The Search for the Origins of Consciousness. New York: Harper Collins Publishers.

Klíma, B. (1991). Zur Frage von gelochten Knochen im mährischen Paläolithikum. Anthropologie, 29, 73-78.

Kroeber, A. L. (1900). The Eskimo of Smith Sound. Bulletin of the American Museum of Natural History, 12, $265-327$.

Kumar, G., Narvare, G., \& R. Pancholi (1988). Engraved Ostrich Eggshell Objects: New Evidence of Upper Palaeolithic Art in India. Rock Art Research, 5, 43-53.

Kumar, G., Sahni, A., Pancholi, R. K., \& Narvare, G. (1990). Archaeological Discoveries and a Study of Late Pleistocene Ostrich Eggshells and Eggshell Objects in India. Man and Environment, 15, 29-40.

Leroi-Gourhan, A. (1982). The Archaeology of Lascaux Cave. Scientific American, 246, 80-88. http://dx.doi.org/10.1038/scientificamerican0682-104

Marshack, A. (1991). A Reply to Davidson on Mania and Mania. Rock Art Research, 8, 47-58.

Martin, H. (1907-1910). Récherches sur l'évolution du Moustérien dans le gisement de la Quina (Charente). Industrie osseuse. Vol. 1, Paris: Schleicher Frères.

McBrearty, S., \& Bbrooks, A. S. (2000). The Revolution That Wasn't: A New Interpretation of the Origin of Modern Human Behavior. Journal of Human Evolution, 39, 453-563. http://dx.doi.org/10.1006/jhev.2000.0435

Mitchell, R. W. (1993). Mental Models of Mirror-Self-Recognition: Two Theories. New Ideas in Psychology, 11, $295-325$. http://dx.doi.org/10.1016/0732-118X(93)90002-U

Mitchell, R. W. (1997). Kinesthetic-Visual Matching and the Self-Concept as Explanations of Mirror-Self-Recognition. Journal of the Theory of Social Behaviour, 27, 18-39. http://dx.doi.org/10.1111/1468-5914.00024

Mitchell, R. W. (2002). Subjectivity and Self-Recognition in Animals. In M. R. Leary, \& J. P. Tangney (Eds.), Handbook of Self and Identity (pp. 567-595). New York: Guilford Press.

Morin, A. (2003). Let’s Face It. Evolutionary Psychology, 1, 177-187.

Morse, K. (1993). Shell Beads from Mandu Mandu Creek Rock-Shelter, Cape Range Peninsula, Western Australia, Dated before 30,000 b.p. Antiquity, 67, 877-883.

Mottl, M. (1951). Die Repolust-Höhle bei Peggau (Steiermark) und ihre eiszeitlichen Bewohner. Archaeologica Austriaca, 8 , $1-78$.

Muzzolini, A. (1995). Les images rupestres du Sahara. Préhistoire du Sahara 1, Toulouse.

Nadel, D., Danin, A., Werker, E., Schick, T., Kislev, M. E., \& Stewart, K. (1994). 19,000-Year-Old Twisted Fibers from Ohalo II. Current Anthropology, 35, 451-457. http://dx.doi.org/10.1086/204303

Narr, K. J. (1966). Miolithische Kulturen von Westafrikabis Ostasien. In K. J. Narr (Ed.), Handbuch der Urgeschichte, Band 1: Ältere und Mittlere Steinzeit. Jäger- und Sammlerkulturen (pp. 349-367). Bern and München: Francke Verlag.

Nelson, E. W. (1899). The Eskimo about Bering Strait. In J. W. Powell (Ed.), Eighteenth Annual Report of the Bureau of American Ethnology to the Secretary of the Smithsonian Institution, 1896-97, Part I (pp. 19-526). Washington DC: Government Printing Office.

Nieuwenhuis, A. W. (1904). Kunstperlen und ihre kulturelle Bedeutung. Internationales Archiv für Ethnographie, 14, 136154.

Prestwich, J. (1859). On the Occurrence of Flint-Implements, Associated with the Remains of Extinct Mammalia, in Undisturbed Beds of a Late Geological Period. Proceedings of the Royal Society of London, 10, 50-59.

http://dx.doi.org/10.1098/rspl.1859.0019

Pringle, H. (1997). Ice Age Communities May Be Earliest Known Net Hunters. Science, 277, 1203-1204. http://dx.doi.org/10.1126/science.277.5330.1203

Sahni, A., Kumar, G., Bajpai, S., \& Srinivasan, S. (1990). A Review of Late Pleistocene Ostriches (Struthio sp.) in India. Man and Environment, 15, 41-47.

Seeley, W. W., Carlin, D. A., \& Allman, J. M. (2006). Early Frontotemporal Dementia Targets Neurons Unique to Apes and Humans. Annals of Neurology, 60, 660-667. http://dx.doi.org/10.1002/ana.21055

Semenov, S. A. (1964). Prehistoric Technology. London: Londres, Cory, Adams and Mackay.

Smith, W. G. (1894). Man the Primeval Savage. London: E. Stanford.

Stepanchuk, V. N. (1993). Prolom II, a Middle Palaeolithic Cave Site in the Eastern Crimea with Non-Utilitarian Bone Artefacts. Proceedings of the Prehistoric Society, 59, 17-37. http://dx.doi.org/10.1017/S0079497X0000373X

Striedter, K. H. (1984). Felsbilder der Sahara. München: Prestel-Verlag. 
Swartz, K. B. (1997). What Is Mirror Self-Recognition in Nonhuman Primates, and What Is It Not? In J. G. Snodgrass, \& R. L. Thompson (Eds.), The Self across Psychology: Self-Recognition, Self-Awareness, and the Self-Concept (pp. 65-71). New York: New York Academy of Sciences.

Tang, H. S. (1993). Theory and Methods in Chinese Rock Art Studies. Rock Art Research, 10, 83-90.

Warner, C., \& Bednarik, R. G. (1996). Pleistocene Knotting. In J. C. Turner, \& P. van de Griend (Eds.), History and Science of Knots (pp. 3-18). Singapore: World Scientific. http://dx.doi.org/10.1142/9789812796134_0001

Wendt, W. E. (1974). Art mobilier aus der Apollo 11 Grotte in Südwest-Afrika. Acta Praehistorica et Archaeologica, 5, $1-42$.

White, R. (1989). Production Complexity and Standardization in Early Aurignacian Bead and Pendant Manufacture: Evolutionary Implications. In P. Mellars, \& C. Stringer (Eds.), The Human Revolution: Behavioral and Biological Perspectives on the Origins of Modern Humans (pp. 366-390). Edinburgh: Edinburgh University Press.

White, R. (1992). Beyond Art: Toward an Understanding of the Origins of Material Representation in Europe. Annual Review of Anthropology, 21, 537-564. http://dx.doi.org/10.1146/annurev.an.21.100192.002541

White, R. (1993a). A Social and Technological View of Aurignacian and Castelperronian Personal Ornaments in SW Europe. In V. Cabrera Valdés (Ed.), El origen del hombre moderno en el suroeste de Europa (pp. 327-357). Madrid: Ministerio de Educación y Ciencia.

White, R. (1993b). Technological and Social Dimensions of Aurignacian-Age Body Ornaments across Europe. In H. Knecht, A. Pike-Tay, \& R. White (Eds.), Before Lascaux: The Complex Record of the Early Upper Paleolithic (pp. 277-299). Boca Raton, FA: CRC Press.

White, R. (1995). Comment on R.G. Bednarik 1995. Current Anthropology, 36, 623-625.

Ziegert, H. (1995). Das neue Bild des Urmenschen.Uni hh forschung, 30, 9-15.

Ziegert, H. (2010). Adam kam aus Afrika-aber wie? Zur frühesten Geschichte der Menschheit. Hamburg: University of Hamburg. 